\title{
LER O FÚCSIA, ENTRAR EM UM MÉNAGE: O LIVRO FÚCSIA - DA LINGUAGEM TRIPARTIDA (2017), DE DIOGO DA COSTA RUFFATO
}

TO READ FUCHSIA, TO ENTER A MÉNAGE: O LIVRO FÚCSIA - DA LINGUAGEM TRIPARTIDA (2017), BY DIOGO DA COSTA RUFFATO

Bruna Kalil Othero*

* brunakalilof@gmail.com

Formada em Letras pela UFMG e mestranda no Programa de PósGraduação em Estudos Literários da Faculdade de Letras da UFMG.

Li esse livro como quem faz um ménage. Entre duas pessoas, num turbilhão dos corpos. Essa leitura sexual foi um pedido do livro: leitora, tire as roupas e junte-se a nós. Quem é esse nós? A primeira pessoa é Diogo da Costa Rufatto (1989), autor e criador dos narradores. A segunda pessoa falo mais a frente. E a terceira sou eu, é você, o leitor, a leitora, quem possui esse livro nas mãos, quem o abre, percorrendo-o pela via tátil - a leitura é, ela mesma, um grande ato erótico.

O Livro fúcsia - da linguagem tripartida (Urutau, 2017) é o terceiro livro de Rufatto e possui prefácio e orelha, respectivamente, das escritoras Laura Cohen Rabelo e
Flávia Péret, e posfácio do psicanalista Rodrigo Moreira de Almeida. Dividido em três contos, possui também uma capa e um projeto gráfico que traz desenhos em três cores: um rosa dominante, azul e preto. O número é uma possível chave de leitura para o volume.

O primeiro conto, "Eu. O vento. A coisa. (ou da linguagem de constituição)", como diz o título, tem a função de constituir a linguagem e o tom utilizados ao longo do livro. É apresentada ao leitor uma estética que quebra com as tradições clássicas da narrativa linear, apesar de se servir da forma já conhecida de letras maiúsculas no início das frases e pontuação usual. $\mathrm{O}$ rompimento narrativo, aqui, 
1. RUFATTO. O livro fúcsia - da linguagem tripartida, p. 16-19.

2. BARTHES. $O$ prazer do texto, p. 20 está na maneira de contar a história - por meio de um abismo cheio de epifanias, as cenas vão se montando, um mosaico de fragmentos, pensamentos, impressões: "Veja eu, agora, comecei a falar de uma coisa e veio outra, e voltei, e fui de novo, [...] estarei pulando partes da minha história. Não que isso importe muito, há sempre a opção de reordenar".

Roland Barthes, em O prazer do texto, teoriza sobre "textos de prazer" e "textos de gozo", uma espécie de literatura que teria como objetivo o conforto ou a provocação do seu leitor:

Texto de prazer: aquele que comenta, enche, dá euforia aquele que vem da cultura, não rompe com ela, está ligado a uma prática confortável da leitura. Texto de gozo: aquele que põe em estado de perda, aquele que desconforta (talvez até um certo enfado), faz vacilar as bases históricas, psicológicas do leitor, a consistência de seus gostos, de seus valores e de suas lembranças, faz entrar em crise em relação com a linguagem. ${ }^{2}$

O texto de Diogo, portanto, seria de gozo, por incitar uma extrapolação de gêneros - frequentemente, esbarra nos limites entre a prosa e a poesia -, e desejar tensionar o limite da linguagem - ainda que esteja, irremediavelmente, preso a ela.
E por falar em gozo, é aqui que entra a segunda pessoa do nosso ménage: a consagrada escritora Hilda Hilst (1930-2004), mais conhecida pela sua obra pornográfica, com quem Diogo realiza um forte diálogo de referências e formas. A começar pela epígrafe da obra, um trecho do poema "Filó, a fadinha lésbica", o qual conta a história de uma fadinha cuja genital, à noite, se transformava em um

\section{bastão grosso}

De início igual a um caroço

Depois...

Ia estufando, crescendo

E virava um troço

Lilás

\section{Fúcsia}

Bordô

Ninguém sabia a cô do troço

da Fadinha Filó. ${ }^{3}$

É desse poema, marcado pelo tom sexual, que surge o título do volume. Rufatto, em entrevista ao canal Estratégias Narrativas - projeto coordenado pela escritora Laura Cohen, autora do prefácio do livro -, reafirma esse diálogo com Hilst, ao discorrer sobre a cor fúcsia: "essa palavra [fúcsia] vem de eu ler Hilda Hilst, que é uma grande influência pra mim, principalmente nesse livro, [...] acho

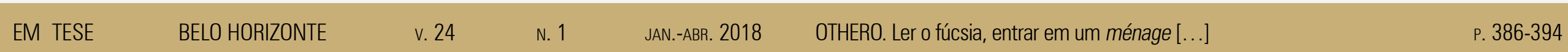


4. RABELO. Constança Guimarães e Diogo da Costa Rufatto parte 2: os livros - estratégia parte 2: os livros - estratégias
narrativas. Disponível em: <https://www.youtube.com/ Acesso em: 8 maio 2018 .

RUFATTO. O livro fúcsia - da linguagem tripartida, p. 15.

6. HILST. A obscena Senhora D, p. 17

7. RUFATTO. O livro fúcsia - da linguagem tripartida, p. 30 que eu escrevi esses três textos colocando ela de algumas formas, a partir dela". ${ }^{4}$

O diálogo, porém, não se restringe ao título, marcando-se presente também na estética do texto e na construção das personagens. Isso ocorre, sobretudo em relação à narradora do primeiro conto, que se apresenta como "eu-nada, eu-esvaída-de-mim, eu-esquecida". ${ }^{5}$ Ora, um leitor de Hilda Hilst imediatamente se lembra de Hillé, a intensa protagonista do romance A obscena Senhora D (1982): "Vime afastada do centro de alguma coisa que não sei dar nome, nem porisso irei à sacristia, teófaga incestuosa, isso não, eu Hillé ta mbém chamada por Ehud A Senhora D, eu Nada, eu Nome de Ninguém”. ${ }^{6}$ A personagem de O livro fúcsia é uma mulher em crise sobre si mesma, a sua história e o seu eu:

Quem é esta que me toma e vomita palavras, quem é esta que se movimenta e flui, quem é esta que habita este corpo? Quem é esta que eu desconheço e de quem é este corpo que habito? [...] O que sou, o que eu sou? Palavra? Não. Sou corpo de carne e com as palavras me reintegrarei, ordenarei minhas partes e meus ligamentos.

Nesse sentido, o tom da obra é dado pelo viés feminino, lugar onde a potência fértil de criação é transferida do ventre ao texto: "não me descem, todos os meses, as impurezas a través do sangue. Que desçam através de palavras". De maneira análoga, a figura feminina em questionamento é uma constante na obra hilstiana, aparecendo não só em Hillé, mas também na poesia

É meu este poema ou é de outra? Sou eu esta mulher que anda comigo

$[\ldots]$

Sou eu que a mim mesma me persigo Ou é a mulher e a rosa que escondidas

(Para que seja eterno o meu castigo)

Lançam vozes na noite tão ouvidas?

Não sei. De quase tudo não sei nada.

A mulher não sou eu. E perturbada

A rosa em seu destino, eu a persigo

Em direção aos reinos que inventei. ${ }^{9}$

A linguagem de constituição de Rufatto, portanto, se insere na tradição do fluxo vertiginoso utilizada por Hilst, cujo marco foi a publicação do primeiro livro em prosa da a utora, o revolucioná rio Fluxo-floema (1970). A obra reúne cinco contos, todos seguindo uma estética polifônica, não
RUFATTO O livro fúcsia - da linguagem tripartida, p. 29.
9. HILST. Exercícios, p. 218.
EM TESE
BELO HORIZONTE
v. 24
N. 1
JAN-ABR. 2018
OTHERO. Ler o fúcsia, entrar em um ménage [...]
P. 386-394 
linear, composta por vozes dissonantes e complexas sucessões de pensamentos e cenas - forma aproveitada pelo autor, e sobre a qual ele demonstra um domínio preciso e raro na literatura contemporânea, território que, inexplicavelmente, ainda é dominado pela repetição da estética clássica e linear.

Nesse primeiro conto, são três elementos que nos interessam: eu, o vento, a coisa. Ao longo da narrativa, esses três elementos vão se misturando e se partindo, enquanto ouvimos esse eu, uma narradora, contar sua história sobre a descoberta do autoconhecimento, do corpo, e da sexualidade, passando por um casamento e um relacionamento posterior com outra pessoa. Ao percorrer o corpo, o tom do texto vai de encontro ao erótico:

comecei a me movimentar na minha cama, me debatia, me esfregava entre os lençóis, corria as mãos pelo meu corpo e aquilo era bom e eu não sabia explicar e era ruim também e eu não sei explicar, eu já não pensava mais, nunca mais eu iria pensar, pensar não era bom, era bom aquilo, aquela coisa, ali, era boa, a coisa, meu corpo suava cada vez mais e eu nem me importava, era bom suar daquele jeito, era bom aquele calor espalhado por todo o meu corpo, eu me sentia viva, cada vez mais viva e pulsante, aguçada e acho que comecei a fazer barulhos sem nem perceber porque quando me dei conta minha mãe estava no quarto com uma cara muito apavorada misturada com raiva. De um castigo, parti pra outro, mais severo. Minha mãe me deu um tapa na cara e disse "recomponha-te", me tomou pela mão e foi me puxando e eu disse "mãe, onde a senhora vai me levar? e ela respondeu "à igreja, ao padre, vais te confessar", "mas eu não quero", "vais, é o único jeito de te livrares deste pecado". E eu nem sabia que pecado tinha cometido. Sabia que tinha algo a ver com aquele prazer que sentira me esfregando em minha cama, que era bom e era ruim. Devia ser por isso, sentir aquele prazer era pecado e era ruim. A coisa. Então integrar-se com todas as coisas era uma coisa feia. ${ }^{10}$

A coisa, portanto, é o prazer, reprimido pela religião. Segundo Moraes, o que acontece é algo como "colocar em cena o corpo capturado no momento do prazer, submetido ao desregramento dos sentidos, à desordem que caracteriza o erotismo". ${ }^{11}$ Enquanto, para a mãe, o gozo é pecado, para a filha, ele se aproxima da fé, de uma experiência de êxtase. Essa dicotomia entre sagrado e profano é formalizada por Bataille, concluindo que tudo é face da mesma moeda:

a experiência erótica, entretanto, é vizinha da santidade. [... a mbas as experiências têm uma intensidade extrema. Quando falo de santidade, falo da vida que apresenta a nós de uma realidade sagrada determina, de uma realidade que podemos
10. RUFATTO. O livro fúcsia - da linguagem tripartida, p. 21.

1. MORAES. O corpo impossível, p. 69.
EM TESE
BELO HORIZONTE
v. 24
N. 1
JAN.-ABR. 2018
OTHERO. Ler o fúcsia, entrar em um ménage [...]
P. 386-394 
13. RUFATTO. O livro fúcsia - da linguagem tripartida, p. 23

14. RUFATTO. O livro fúcsia - da linguagem tripartida, p. 31.

15. RUFATTO. O livro fúcsia - da linguagem tripartida, p. 34 nos transtornar até o limite. [...] Quis dizer dessas duas experiências que uma nos aproxima dos outros homens e que a outra no aparta deles, nos deixa na solidão. ${ }^{12}$

Esse prazer, porém, só é bom consigo mesma, e se torna violento quando o elemento masculino, personificado na figura do marido, é inserido: "meu marido na noite de núpcias, a noite mais sofrida da minha vida. Noite de medo, que aquilo não me era conhecido. Eu nem sequer sabia o que de mim era esperado, mesmo sem vontade. Mas fiz" ${ }^{13}$ Porém, esse lado viril do marido não dura muito tempo Quando surge um terceiro elemento nesse relacionamento - um outro cha mado "gente. Nem homem, nem mulher Gente",$-{ }^{14}$ ele se envolve, primeiramente, com o marido, que demonstra um lado surpreendentemente feminino. Há, dessa forma, uma desconstrução dos papéis de gênero, e nos deparamos com confluências entre masculino e feminino:

para que meu marido se justificasse em meu ouvido "eu precisava sentir como era ser o mistério, como era ocultar a virilidade, como era sugar a macheza, como era ser fêmea, você!" E foi assim que eu tirei minha roupa pela primeira vez. Foi assim que eu me inaugurei no sexo como mulher, com eu-oca, com ele, com a gente..$^{15}$
No final do conto, descobrimos que a narradora estava presa em um hospital de freiras todo o tempo, numa referência ao histórico movimento de encarcerar mulheres, seja em prisões, hospícios ou conventos, quando elas se tornavam ameaças à ordem vigente. Por fim, o que fica desse "Eu. O vento. A coisa" é a intensidade do número três, a fragmentação do eu e desejo da fusão: "Como poderemos nos fundir? Seremos eu? Seremos ela? Seremos outra?". ${ }^{16}$

O segundo texto, "Língua paterna (ou da linguagem de afeição)", tem esse título provocador: já nos adianta que tratará da masculinidade por outro viés, já que ela é tradicionalmente associada à frieza e à força, enquanto a afetividade e o sentimentalismo são reservados à esfera do feminino. Com uma forma mais livre, o conto não possui letras maiúsculas nem ponto final, tendo o ritmo marcado por vírgulas. Aqui, somos apresentados a Fragero, um nome que remete à palavra frágil: "nem só o coração da mulher é que tantos segredos guarda, também o de um homem, Fragero, tão resiliente, sério e forte, trabalhador intenso, superfície de pedra". ${ }^{17}$

Esse homem é presenteado com uma peça de arte que retrata uma figueira, possível referência à árvore centenária e mágica da Casa do Sol, fazenda de Hilda Hilst. Esse quadro muda tudo, e é ele quem acorda um lado sensitivo de Fragero:
16. RUFATTO. O livro fúcsia - da linguagem tripartida, p. 27. 
18. RUFATTO. O livro fúcsia - da linguagem tripartida, p. 40

19. RUFATTO. O livro fúcsia - da linguagem tripartida, p. 41

20. RUFATTO. O livro fúcsia - da linguagem tripartida, p. 43 era uma vontade de olhar aquele quadro, de dar-lhe tempo para que adentrasse seja lá o que fosse em sua alma, na alma de Fragero, que tanto precisava de alimento, mas o compromisso era o trabalho e Fragero deu uma olhadela rápida no quadro e foi dar alimento ao corpo, e foi vestir o corpo com as roupas do homem que aprendera a ser, da pessoa que construíra, Fragero, sério, sóbrio e sólido. ${ }^{18}$

Há, aqui, um contraste entre o alimento da alma, a arte; e o alimento do corpo, a comida, que deve ser comprada por meio do trabalho capitalista. A contemplação da arte, portanto, é uma reviravolta na história desse homem, que se transforma: "Fragero a travessou o dia tentando ser Fragero, mas Fragero já era outro, já vira o quadro, [...] parou em frente à imagem e contemplou" ${ }^{19}$

Para viver esse outro momento, em direção à liberdade, ele desmonta a performance da masculinidade, e entra em conta to com sua própria natureza, na preparação para uma nova jornada. Nessa viagem, perde os pelos do corpo, símbolo tão masculino, e fica exposto, nu: "e foi assim que Fragero sentiu cair um primeiro fio [...] e de outro em outro todos os fios foram caindo, e ficou Fragero sem pelos, sem barba, sem cabelos, enqua nto ia, naquela jornada, pela estrada de vento". ${ }^{20}$ Pelas lágrimas, o atestado da sensitividade, Fragero se torna Frage, um homem frágil, que pode, finalmente, gritar: e quanto mais Fragero caminhava mais sentia lhe encherem a cara as lágrimas, elas que Fragero esquecera, olvidadas por anos de máscara, contidas, retidas, margeadas por solo arenoso, de construção fraca, e vendo-se Fragero completamente em solo, solitário, Fragero sofreu uma apócope e não pôde mais conter o grito "sou Frage, Fraaaaaaaaaaaaaaaaaaageeeeeeeeeeeee".

No encerramento do conto, o destino final da jornada é deixado em aberto, mas uma interpretação interessante é a de que Frage entrou no quadro que o impressionou, encontrando a figueira vermelha: "Frage deu mais uns passos e chegou, ali, na árvore, [...] que se expôs em tronco revelando uma luz, uma força, um fogo-fátuo vermelho, rubro, intenso, carmim, escarlate”. ${ }^{22}$ Há, por fim, uma renovação do masculino, que, impedido pela natureza de dar à luz, encontra uma alternativa: "chorou, as lágrimas de toda a sua história e do tempo, as lágrimas do mundo, Frage chorou e apagou o fogo, lavando a pele e renovando a memória, [...] não podendo dar à luz, como num golpe semântico, deu-se à lucidez, guardou o segredo no coração". ${ }^{23}$ O segredo guardado no seu coração de homem, citado no início do conto, é quem também o fecha, sem ponto final, criando uma narrativa circular.

O terceiro e último conto, "HLH (ou da linguagem de destituição)", é o momento de crise da linguagem, que já
21. RUFATTO. O livro fúcsia - da linguagem tripartida, p. 44

22. RUFATTO. O livro fúcsia - da linguagem tripartida, p. 45.

23. RUFATTO. O livro fúcsia - da linguagem tripartida, p. 45.

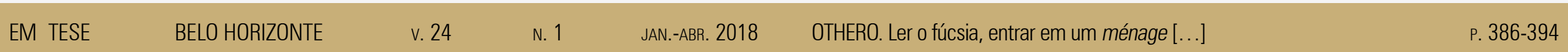


24. RUFATTO. O livro fúcsia - da linguagem tripartida, p. 47

25. RUFATTO. O livro fúcsia - da linguagem tripartida, p. 47

26. RUFATTO. O livro fúcsia - da linguagem tripartida, p. 47.

27. RUFATTO. O livro fúcsia - da linguagem tripartida, p. 48

28. RUFATTO. O livro fúcsia - da linguagem tripartida, p. 49 passou pela constituição e pela afeição. Nesse contexto, ele é o mais metalinguístico dos três, como se pode perceber na sua primeira frase: "Eu mesmo vou me apresentar: sou o narrador desta história”, ${ }^{24}$ abertura que dá o tom de todo o texto, uma conversa explícita entre os elementos da narrativa: narrador, leitor, personagem. Novamente, há o número três, o que propicia uma brincadeira na própria linguagem: "escolho [...] narrar esta história em terceira pessoa, inclusive quando eu decidir falar de mim". ${ }^{25}$ Nesse sentido, as pessoas do discurso se misturam, e, como numa analogia, o narrador explica: "chega um momento em que a criança percebe que o bebê é também o eu. São duas instâncias separadas, mas que são a mesma. É quando se percebe que o eu é um espelhamento do ele, e vice-versa. Isto é uma pista, leitor, fique a tento" ${ }^{26}$ Diante dessa hibridização de vozes, o narrador, que conta em terceira pessoa, apresenta-se como o personagem Lierot, a nagra ma de "leitor". O ponto de partida dessa história é o momento em que Lierot apreende a linguagem humana, "uma linguagem toda materna, inexprimível, feminina e completa". ${ }^{27}$ Contudo, esse personagem entra em crise em relação ao sentido da vida, e só encontra algum momento de avanço enquanto produzia artisticamente. E é nesse momento, imerso em pensamentos estéticos, que "pela primeira vez brotou em sua mente o pensamento sobre a letra $\mathrm{H}[. ..] \mathrm{du}-$ pla de si mesma", ${ }^{28}$ levando-nos de novo a pensar em Hilda
Hilst, cujas iniciais são HH. Nessa atmosfera de duplos, Lierot encontra dois irmãos gêmeos, chamados H. e H., e os três começam um relaciona mento:

esta é uma história triangular, e como sou L., uma letra cujas metades não são iguais, onde não há simetria, mas um ângulo reto, os $90^{\circ}$ de todo triângulo retângulo, [...] pois que seja assim, a soma de Lierot vezes seu duplo e narrador vezes seu duplo fluindo do vértice da letra $L$ igualando à hipotenusa vezes a hipotenusa, H.H. ${ }^{29}$

À medida que a relação avança, entramos em território extremamente erótico. Essa sensualidade nasce primeiramente na linguagem, para depois ir ao corpo: "Confesso, eu deliro e fabulo. Foi desse modo que conheci o sexo". ${ }^{30}$ Após o início na imaginação, o sexo vai para o real, quando o narrador descreve um ménage entre os três homens, as três letras, HLH:

aí percebi que tinham baixado os olhos e me dei conta de que eu tinha uma ereção, e me dando de conta de mim olhei para os genitais de $\mathrm{H}$. e H., os quais eram idênticos, mesmo ta manho, mesmo inchaço e mesmas imperfeições, eram simétricos até mesmo em suas assimetrias e lembro que os dois se voltaram um para o outro e eram um espelho, um refletido no outro. ${ }^{31}$
29. RUFATTO. O livro fúcsia - da linguagem tripartida, p. 50

30. RUFATTO. O livro fúcsia - da linguagem tripartida p. 51.

31. RUFATTO. O livro fúcsia - $d a$ linguagem tripartida, p. 52 
32. RUFATTO. O livro fúcsia - da linguagem tripartida, p. 53
Essa semelhança absurda entre os gêmeos aparece como um fetiche, e L. é convidado a explorar os seus corpos, procurando diferenças entre os dois.

A língua, palavra tão cara à obra de $\mathrm{HH}$ - lembremos de O caderno rosa de Lori Lamby (1990), o escandaloso livro narrado pela pequena prostituta de 8 anos, que descobria a língua portuguesa da literatura enquanto lambia e era la mbida por homens mais velhos -, aparece ta mbém aqui, nesses dois sentidos:

e H. me disse para então exercitar a minha língua no seu falo, [...] e pensei que esse seria um bom trocadilho na hora de relatar, mas ta mbém pensei que nunca haveria de relatar aquilo tudo porque era absurdo, porque estar demasiado entregue àquela aventura carnal não era condizente, embora eu não conseguisse lembrar da palavra condizente porque ali eu exercitava a língua de outra maneira. ${ }^{32}$

Quando a penetração finalmente chega, é o momento em que L. se abre, se entrega completamente aos dois irmãos, numa explosão de afeto, que o leva ao limite do corpo, do prazer, da intensidade: "primeira invasão de H. [...] sufocou minha expressão com sua boca e naquele beijo senti ta manho afeto que continuei a me entregar e não sei como fui me abrindo mais, e mais e mais, e aquele torpor todo me fez sim lembrar-me da palavra mais". ${ }^{33}$ Nesse sexo a três, esse ménage simétrico, L. percebia os dois como um só, e um só como dois: "e disse 'está sentindo a individualidade?' e eu sentia, era $\mathrm{H}$. e era $\mathrm{H}$. mas eu sabia cada movimento que cada $\mathrm{H}$. fazia em mim, eram dois, eram um, eram o mesmo, eram duplos". ${ }^{34}$

Por fim, após percorrer os três contos, chega mos à conclusão que tive, durante a leitura: ler O livro fúcsia é estar em um ménage. Sempre somos três, confundindo-se em nós mesmos: autor, leitor, obra. HLH:

eu, o pronome daquela mesóclise, eu que ta mbém era me, era mim, eu que ta mbém era outro, Lierot bagunçado, narrador, desordenado por H.H., H.Lierot.H, devassado, entremeado, respirando cada vez mais rápido, duplicado eu me vi a mim, no espelho, imaginado e real, outra vez HLH ofegante, [... embaralhou-se a ordem, HLEITORH. ${ }^{35}$

Lierot, ou agora Leitor, termina o conto (e o livro) desaprendendo a linguagem humana, após alcançar o êxtase maior do corpo: o gozo. Essa é também a nossa sensação, como leitores, como lierotes: nada sei desse texto, nada quero saber, só sei que gozo, e é gozando que continuo a ler.
33. RUFATTO. O livro fúcsia - da linguagem tripartida, p. 53.

34. RUFATTO. O livro fúcsia - da linguagem tripartida, p. 53.

35. RUFATTO. O livro fúcsia - da linguagem tripartida, p. 54.
EM TESE
BELO HORIZONTE
v. 24
N. 1
JAN.ABR. 2018
OTHERO. Ler o fúcsia, entrar em um ménage [...]
P. 386-394 


\section{REFERÊNCIAS}

BARTHES, Roland. O prazer do texto. Trad. J. Guinsburg. São Paulo: Perspectiva, 2015

BATAILLE, Georges. 0 erotismo. Trad. Fernando Scheibe. Belo Horizonte: Autêntica, 2014

HILST, Hilda. A obscena Senhora D. São Paulo: Globo, 2001.

HILST, Hilda. Exercícios. São Paulo: Globo, 2002.

HILST, Hilda. Fluxo-floema. São Paulo: Globo, 2002.

HILST, Hilda. O caderno rosa de Lori Lamby. São Paulo: Globo, 2002.

HILST, Hilda. Filó, a fadinha lésbica. In: HILST, Hilda. Pornô chic São Paulo: Globo, 2014. p. 234-237.

MORAES, Eliane Robert de. O corpo impossível. São Paulo: lluminuras, 2002

RABELO, Laura Cohen. Constança Guimarães e Diogo da Costa Rufatto - parte 2: os livros - estratégias narrativas. Belo Horizonte: Estratégias Narrativas, 3 nov. 2017. Disponível em: $<>$ https://www youtube.com/watch?v=CkzbUHZ1cf8. Acesso em: 8 maio 2018.

RUFATTO, Diogo da Costa. O livro fúcsia - da linguagem tripartida. São Paulo: Urutau, 2017. 